\title{
Science Museum and University Collaborations for Public Engagement - the Nanoscale Informal Science Education Network (NISE Net)
}

\author{
Larry Bell
}

Strategie Initiatives, Museum of Science, Boston, USA

In 2005, the National Science Foundation issued a solicitation seeking proposals for an effort "intended to foster public awareness, engagement, and understanding of nanoscale science, engineering, and technology through establishment of a Network, a national infrastructure that links science museums and other informal science education organizations with nanoscale science and engineering research organizations." The Museum of Science in Boston collaborated with the Science Museum of Minnesota in St. Paul and the Exploratorium in San Francisco to craft the winning proposal. Underlying the solicitation was the notion that university researchers at Nanoscale Science and Engineering Centers and similar organizations had knowledge of this new field of research but little knowledge of informal science education, and that science museum professionals had knowledge about informal science education but little knowledge about nanotechnology. By working together, the two fields could raise the capacities of both to more effectively engage the public in learning about nanoscale science, engineering, and technology.

The work began with exploration of a wide range of possible activities to achieve the intended outcomes, but became more focused over time as the project teams used prototype testing, formative evaluation, advisor and peer critiques, and feedback from intended professional and public audiences to inform the direction of the work on all levels. NISE Net received a second NSF award in 2010 and is now in its ninth and next-to-final year of NSF funding. So its activities have been through a series of changes and adjustments over time and are now fully mature and the Network has grown from 14 institutions in the first year to well beyond the 100 sites for nano education we promised to NSF. We currently count about 500 organizations as involved in the NISE Net with about 250 as highly active.

Pulling together the expertise of a variety of scientists and informal educators on teams working on exhibits, programs, and media, NISE Net has developed an online catalog of educational materials with 337 entries in it, all freely available for download at the NISE Net's website www.nisenet.org. A survey of Network partners in the fall of 2013 showed that the online catalog is one of the two most valuable resources NISE Net has created for its partner organizations. It includes cart demonstrations, classroom activities, games, theater and stage presentations, exhibits, dialogue forums, podcasts, digital images and graphics, online games, videos, training materials, guides for developing and implementing activities, ready to use templates, evaluation tools, and more. While these activities were developed for use in informal learning environments, nearly half of the university-based respondents to the 2013 partner survey reported using NISE Net materials for teaching their college level courses.

In 2008, NISE Net launched an annual nationwide festival of learning about nanotechnology called NanoDays. Each year since then NISE Net has produced a comprehensive kit of materials designed to support NanoDays events, and distributed physical kits to 200 to 250 sites across the U.S. reaching every state, DC, and Puerto Rico. The kits include everything you need to host a NanoDays event: hands-on activities to do with the public, programs and presentations, videos, graphics, training materials, guides of 
various kinds, marketing materials, and even colorful tablecloths and temporary tattoos. NanoDays events themselves have been estimated to have about a half million visitor contacts, but partners report using the kits for a wide range of activities year round, including table top activities, K-12 school outreach activities, special events such as family nights and festivals, science camps, outreach activities with community partners, professional development for museum staff or school teachers, longer museum programs, ongoing displays, as well as in college courses, as previously mentioned. The NanoDays physical kit was rated by partners as the most valuable resource provided by NISE Net. A digital version of the kit is also available online for those who don't receive a physical kit or who just want specific components.

To provide something with an ongoing physical presence on the floor of science and children's museums everywhere, NISE Net developed a small-footprint mini-exhibition called Nano, copies of which have been distributed so far to 49 locations, with 44 more to be fabricated and distributed in the next year and a half. When all the copies are distributed, the Nano exhibitions will reach close to 10 million members of the public each year.

In addition to all the NanoDays kit and online catalog of educational materials developed and distributed by the NISE Net, in-person professional development is the next most valuable resource for member organizations according to the fall 2013 partner survey. NISE Net professional development activities have covered a wide range of topics only a couple of which will be mentioned here.

Science communication training for early career scientists has been an important aspect of the NISE Net and has taken several forms. Many graduate students from nanoscale research centers participate in annual NanoDays events at sites around the country. The science and children's museums where these sites take place provide training for the participants prior to the events but significant learning also takes place from interacting with the public. In connection with research centers headquartered at Harvard and Northeastern Universities, the Museum of Science developed workshops on science communication for grad students and for REU students (research experience for undergraduates.) Especially since nanotechnology fields are multi-disciplinary, training to communicate better with the public also helps better communication on research teams. The Materials Research Society has incorporated science communication training into a series of workshops given at it's twice a year professional conferences. These workshops focus on presentation design, poster design, and working with the media. At the 2014 Annual Meeting of the American Association for the Advancement of Science (AAAS), Museum of Science staff have worked with the AAAS to develop a Presentation Rx Clinic that runs throughout the four day meeting to help presenters communicate better in their conference presentations.

NISE Net has partnered for some time with the Center for Nanotechnology in Society and recently developed a set of educational resources, workshops, and a guide to Nanotechnology and Society that provide a framework to help museum staff and visitors feel empowered to reflect on the relevance of nanotechnology in their lives through open-ended conversation. The guide considers how nanotechnologies may affect people and the societies they live in and explores strategies and tips for engaging the public in conversations as part of their learning experience.

Other professional development activities have focused on serving inclusive audiences, people with disabilities, and Spanish-speaking audiences; and on Team Based Inquiry - a strategy for getting the evidence you need to help improve your innovative informal educational efforts. 